\title{
Rice Acreage Estimation Using Sentinel-1A Dual Polarised SAR Data in Udham Singh Nagar (Uttarakhand)
}

\author{
Chetan Kumar Bhatt* and A.S. Nain \\ Department of Agrometeorology, College of Agriculture, G.B. Pant University of Agriculture \\ and Technology, Pantnagar- 263145 (Dist. Udham Singh Nagar, Uttarakhand), India \\ *Corresponding author
}

\begin{tabular}{|l|}
\hline K e y w o r d s \\
ENVI, Remote \\
sensing, SAR, \\
Sentinel-1A, SNAP, \\
SVM
\end{tabular}

\section{Introduction}

Rice is one of the world's major agricultural
crops. It is the staple food of more than 50\%
of the Earth's population (FAO, 2002). Rice is
mainly grown in kharif season and accounts

Rice is one of the world's major agricultural
crops. It is the staple food of more than 50\%
of the Earth's population (FAO, 2002). Rice is
mainly grown in kharif season and accounts

Rice is one of the world's major agricultural
crops. It is the staple food of more than 50\%
of the Earth's population (FAO, 2002). Rice is
mainly grown in kharif season and accounts

Rice is one of the world's major agricultural
crops. It is the staple food of more than 50\%
of the Earth's population (FAO, 2002). Rice is
mainly grown in kharif season and accounts

\section{A B S T R A C T}

Udham Singh Nagar is one of major rice producing area of Uttarakhand state, and it falls in Tarai region. The soils of the region are considered as most fertile land in India and aptly support rice production. Rice is a mainly grown in the rainy season which results in a limited number of cloud-free optical remote sensing images for estimation of rice acreage and its monitoring. Sentinel-1A is a European radar imaging satellite launched in 2014. Sentinel-1A satellite launched as a part of the European Union's Copernicus program which provide Synthetic aperture radar (SAR) data i.e. potentially well suited for rice crop monitoring. It allows observations of different features of earth which are independent of weather conditions and solar illumination. The basic goal behind this study was to apply new generation Sentinel-1A data with dual polarization ( $\mathrm{VH}$ and VV) to rice cropping system mapping and monitoring. SAR data provides an advantage in Land use-land cover (LULC) classification task because these images are not influenced by cloud and leads to increase in mapping accuracy. In the present paper the potential of SAR application for measuring rice acreage during persistent cloud cover has been demonstrated using Sentinel-1A data of European Space Agency. Data were pre-processed by applying European Space Agency's Sentinel Application Platform (SNAP). The SAR dataset classified with a Support Vector Machine (SVM) algorithm provided in ENVI- 5.1 produced the accurate LULC map, which shows that Udham Singh Nagar covers rice area (108,095 Hectares), followed by forest (140,220 Hectares), water body (15,976 Hectares) and fallow land (5060 Hectares) and lastly built up area (2,586 Hectares) with an overall classification accuracy of $92.88 \%$ and a Kappa coefficient of 0.89 . This mapping approach provides an advantage of all-weather mapping capability of the radar sensor with the short revisit period of Sentinel-1A satellite. The mapping results represent an important step toward future tasks of retrieval of crop biophysical parameters using SAR data. for more than 54 percent of the total area under cereals in Uttarakhand state. Rice is grown in all the 13 districts of the state, but maximum area (33\%) is under district Udham Singh Nagar which produces about $48 \%$ of the total rice produced annually in the state. For 
planning and monitoring purposes there is need of up-to-date information on areas which are under rice cultivation and any changes in the cultivated area is very essential for national political decision-makers and for international trade organizations.

So, remote sensing is one such beneficial technology which provides an advantage for effective land cover mapping at a very large scale for up-to-date areas information, and it can be made more cost-effective by increasing the repeatability of observations (Chilar, 2000; Kuemmerle et al., 2013). In this context, airborne as well as space-borne remote sensing data mainly Synthetic Aperture Radar (SAR) data has shown promising results in crop monitoring and classification with a very high accuracy. Backscatter coefficient (the differential scattering cross section per unit volume for a scattering angle of 180') of SAR data in different polarizations and frequencies for crop identification and monitoring have been reported (Toan et al., 1989, 1997; Hoekman and Bouman, 1993; Kurosu et al., 1995; Schotten et al., 1995), using polarimetric scattering matrix that contains information about polarization amplitude as well as phase for rice crop characterization and its classification has also been studied (Freeman et al., 1994; Skriver et al., 1999; Lee et al., 2001; Ainsworth et al., 2009; Haldar et al., 2012; Turkar et al., 2012, Panigrahy et al., 2013).

Attempts have been made to establish relationships between polarization signatures of SAR signal to target rice crop properties (Ulaby et al., 1987; Boerner et al., 1987; Wang and Mo, 1990). This study explored the use of the European radar imaging satellite i.e. Sentinel-1A which was launched in 2014 for synergistic land cover mapping by exploiting SAR data, for rice acreage estimation in Udham Singh Nagar district of Uttarakhand. The Sentinel-1A sensor gives SAR images in both single and dual polarization mode (for detailed descriptions of Sentinel-1A mission see Torres et al., 2012).

The spatial resolution of Sentinel-1A is very high $(5 \times 20 \mathrm{~m}$ in the Interferometric Wide Swath mode), have a large coverage up to 400 $\mathrm{km}$ and also good temporal resolution which provide advantage for accurate land cover mapping (Wagner et al., 2012). Sentinel-1A has frequent revisit time which provides a major advantage over previous launched radar missions, and help in mapping and analyzing the agricultural land covers and phenological dynamics in vegetation, simultaneously with the dual polarization capability and rapid product delivery (Torres et al., 2012). The main objective of this study is to give a methodological framework using SAR data for accurate land cover mapping by applying object-based and spectral classification technique.

\section{Materials and Methods}

\section{Study area and dataset used}

The study area was Udham Singh Nagar district having an area of $2,908 \mathrm{~km}^{2}$ and located in Uttarakhand. Geographically, Udham Singh Nagar is situated between $28.9610^{\circ} \mathrm{N}$ latitude and $79.5154^{\circ} \mathrm{E}$ longitude. The elevation of this place from mean sea level is around 216 meter. The area lies in "tarai" belt located in foot hills of the Himalayas. The area falls under sub-humid and subtropical zone with three distinct seasons. It has summer season from March to June, a rainy season from July to October and cold winter season from November to February. The location map of the study area along with the satellite image of the place has been shown in Figure 1.

For this study, cross-polarized (VH) \& copolarized (VV) Sentinel-1A data acquired on 9 
October 2017 has been used. The attributes of the Sentinel-1A data used in the study have been presented in Table 1. The Sentinel-1A data was downloaded from the ESA Open Access Hub (https://scihub.copernicus.eu).

\section{Ground truth data collection}

The geographic locations and the field boundaries of land use and land covers (LULC) were recorded by using the GPS based mobile mapping unit. Vector layers of these land use and land cover were made by the use of GPS unit which was in UTM projection and these vector layers contained all the detailed information regarding each sampling unit as an output layer. These layers were used on the geo-referenced images for retrieving accurately training set for each class.

\section{Data pre-processing and processing}

Two Sentinel-1A images which cover the entire study area were downloaded from the ESA's Sentinel Scientific Hub (ESA, 2017a). SAR data pre-processing of the Level-1 GRD image was done by using the SNAP (Sentinel Application Platform toolbox) (ESA, 2017b) standard processing methods which were used in the pre- processing of SAR data i.e. calibration, thermal noise removal, mosaicking, resampling to $10 \times 10 \mathrm{~m}^{2}$ spatial resolution and multilook parametrization for both VV and VH polarization images. For the removal of the speckle effects means the distortions comes in the radar images which are also the characteristic of radar images were remunerated by the use of Refined Lee low-pass filter with a $5 \times 5$ kernel, which basically remove the speckle effects by averaging the image and preserving feature edges (Wang et al., 2012).

Radar image backscatter is strongly influenced by the ground surface texture, which gives very important information for classification tasks, and has been used many times for radarbased land cover mapping. So, for calculating the radar derived texture, a module was used which was given in the SNAP, grey-level cooccurring matrix (GLCM) module (texture variance and texture contrast) for both VV and $\mathrm{VH}$ polarization, parameterized with a $5 \times 5$ window size and 32 probabilistic quantization levels which results in four different texture images of the Sentinel-1A data (Clerici et al., 2017). And, these six different texture images were then layer stacked into a 6-layers image:

Sentinel-1A VH and VV amplitude images (2)

Sentinel-1A VH and VV, variance texture images (2)

Sentinel-1A VH and VV contrast texture images (2).

A set of land cover classes were taken which are: built up, rice crop, fallow land, water body and forest. The land use and land cover were selected on the basis of various previous studies. An object-based classification was carried out on ENVI-5.1 by using a supervised classification algorithm, Support Vector Machine (SVM) (Burges, 1998). Support Vector Machine Classification (SVM) is a classification system derived from statistical learning theory. It separates the classes with a decision surface that maximizes the margin between the classes. The surface is often called the optimal hyperplane, and the data points closest to the hyperplane are called support vectors. The support vectors are the critical elements of the training set. Data preprocessing and processing steps are shown in Figure 2.

\section{Results and Discussion}

Initially, the training samples of the five classes: built up, rice crop, fallow land, water 
body forest were selected and, the SVM classifier was applied which trains and runs on the reduced resolution image and ROIs.

The classifier performs training at the lowerresolution level (instead of at full resolution and applying the results at each level) because retraining at each level provides higheraccuracy results for the resampled imagery. So, the sampling steps should be taken carefully for carrying out this classification.

From the sample values chosen for each class, the algorithm determined the best pair of the Gaussian kernel. The use of the radar stacked layers produce acceptable results with SVM classifier. The classification results obtained from the SVM-classification algorithm applied to the integrated layer stack of Sentinel 1A radar data are given in (accuracy statistics in Table 2), thus we discuss here detailed results only from this classification approach. The dominant land cover in the study area is forest $(140,220$ Hectares), followed by rice $(108,095$ Hectares) then water body $(15,976$ Hectares) and fallow land (5060 Hectares) and lastly built up (2,586 Hectares).

Following standard accuracy calculation procedures we estimated an overall accuracy of $92.88 \%$, and a Kappa coefficient of 0.89 as given in Table 2. Omission and commission classification errors were found mainly in rice, fallow land, and water body likely due to the high spectral heterogeneity present in the above classes generated and in rice the errors are also due to the large variety of different cultivars and of vegetation types/growth stages, respectively. A detailed confusion matrix of the integrated datasets SVMclassified map, with overall, user and producer class accuracies, is reported in Figure 3.

Fig.1 Location of the study area with the Satellite image

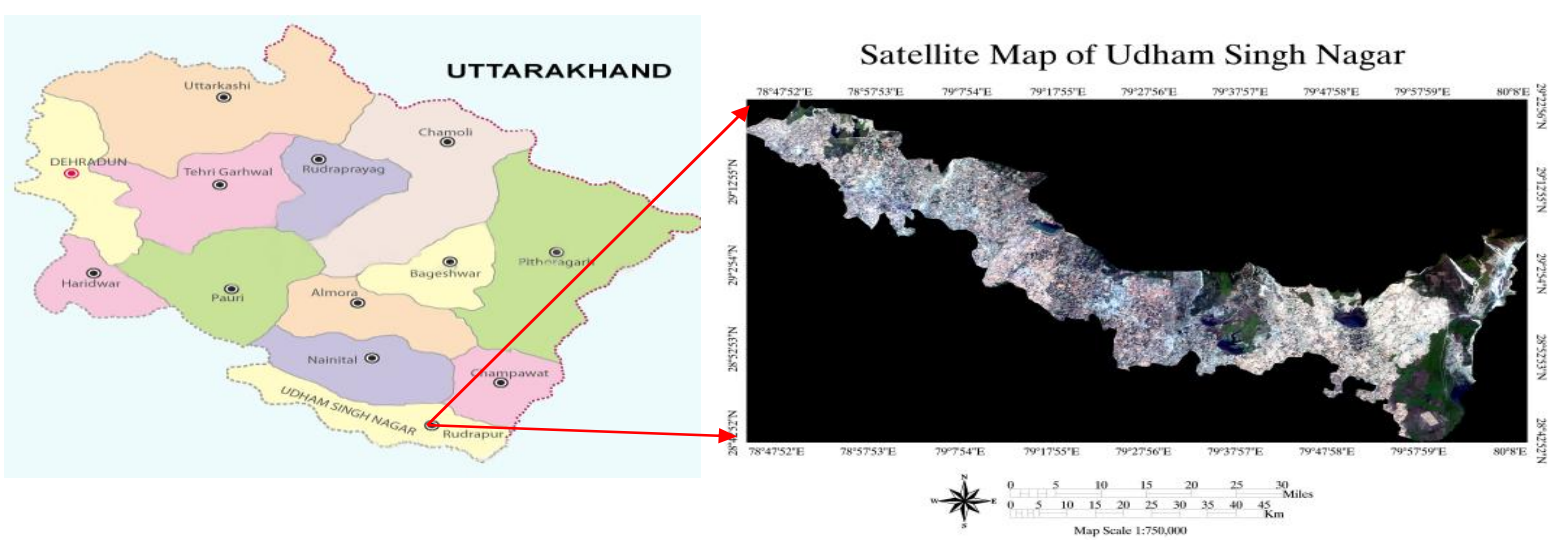

Fig.2 Steps involved in pre-processing and processing

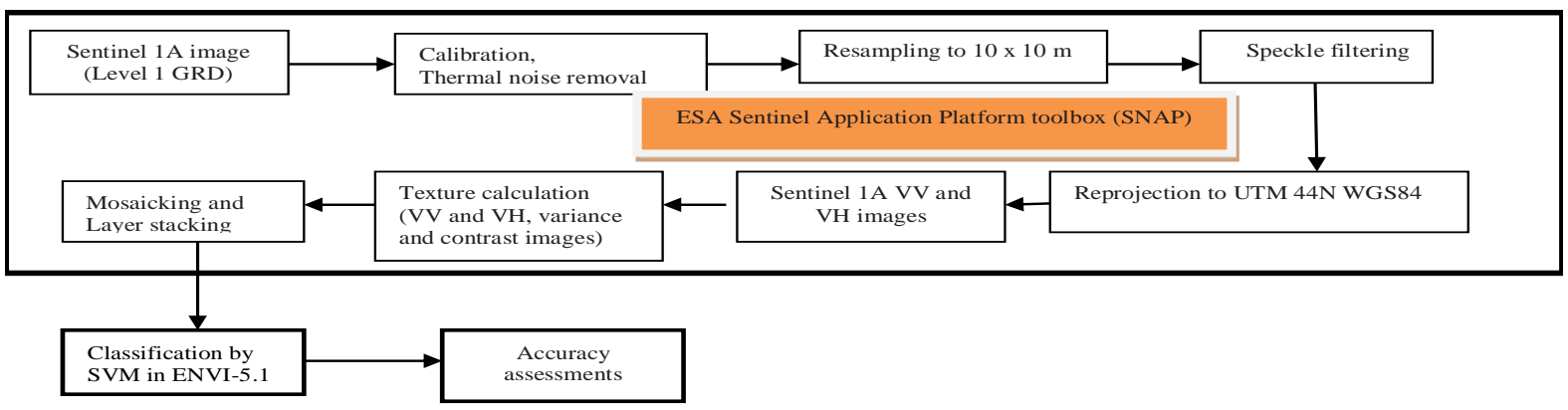


Fig.3 Confusion matrix and classification accuracy measures of the SVM-classified map

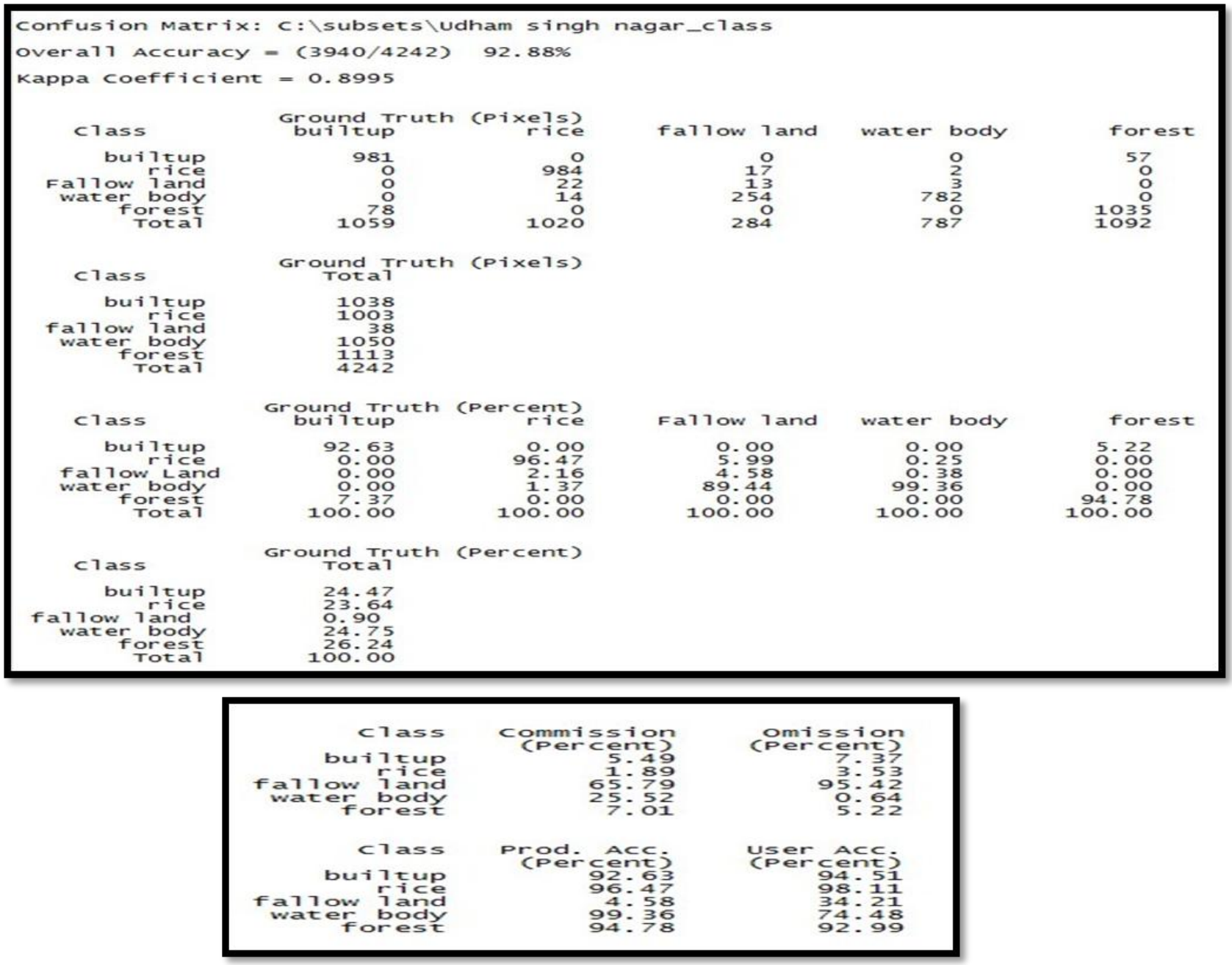

Table.1 Characteristics of sentinel-1A data

\begin{tabular}{|c|c|}
\hline Parameters & Characteristics \\
\hline Polarization & Dual $(\mathrm{VV}, \mathrm{VH})$ \\
\hline Frequency & $5.405 \mathrm{GHz}$ \\
\hline Wavelength & $18 \mathrm{~cm}$ \\
\hline $\begin{array}{c}\text { Spatial Resolution } \\
(250 \mathrm{~km})\end{array}$ & $5 \times 20 \mathrm{~meters}$ \\
\hline Incidence Angle Range & $29.1^{\circ}$ to $46.0^{\circ}$ \\
\hline Pass & Descending \\
\hline
\end{tabular}

Table.2 Overall accuracy and kappa index for the SVM

\section{Sentinel-1A radar layer}

Support Vector Machine
Overall accuracy $(\%)$

$$
92.88 \%
$$

Kappa Coeff.

0.89 
The LULC classification which is carried out by using Sentinel-1A data gives an advantage of retrieving all the information related to the rice crop due to its active sensors, which transmits remotely sensed data continuously even in cloudy and rainy seasons and because this satellite has all weather capability and shorter revisit time period, so it also plays an important role for monitoring of the rice and other crops.

On the basis of the topography of Udham Singh Nagar region, it is significant to note down that in some areas the time of seeding is not the same as specified in the local agricultural calendar.

In order to develop a monitoring system for rice growth more than one SAR image should be taken around the middle rice growing seasons and for this multipolarization SAR data at various frequencies $(\mathrm{C}, \mathrm{X}, \mathrm{L})$, and a good set of ground truth data are recommended.

The resulting LULC map provides an opportunity for the calculation of above ground biomass and carbon content estimation for each LULC category in the Udham Singh Nagar district.

\section{Acknowledgement}

I would like to thank my advisor Dr. A.S. Nain Professor and Head, Department of Agrometeorology, G. B. Pant university of Agriculture and Technology for his mentorship, insightful discussions on the study area and valuable guidance for carrying out this study.

\section{References}

Ainsworth, T. L., Kelly, J. P. and Lee, J.S. 2009. Classification comparisons between dual-pol, compact polarimetric and quadpol SAR imagery. Journal of Photogrammetry and Remote Sensing. 64 (5): 464-471.

Boerner, W.M., Foo, B.Y. and Eom, H.J. 1987. Interpretation of the polarimetric co- polarization phase term in radar images obtained with JPL airborne L-band SAR system. Transactions on Geoscience and Remote Sensing. 25 (1): 77-82.

Burges, C. J. C. 1998. A tutorial on support vector machines for pattern recognition. Data Mining and Knowledge Discovery. 2(2): 121-167.

Chilar, J. (2000). Land cover mapping of large areas from satellites: Status and research priorities. International Journal of Remote Sensing. 21(6): 1093-1114.

Clerici, N., Calderón, C.A.V. and Posada, J.M. 2017. Fusion of Sentinel-1A and Sentinel2A data for land cover mapping: a case study in the lower Magdalena region, Colombia. Journal of Maps. 13(2): 718726.

European Space Agency. (2017a). Sentinel scientific hub. Retrieved October 2017, from https://scihub.copernicus.eu/ dhus/ \#/home

European Space Agency. (2017b). Sentinel application platform. Retrieved July 2017, from http://step.esa.int/main/tool boxes/snap

FAO, 2002. FAO Rice Information, Rome, Food and Agriculture Organization of the United Nations.

Freeman, J., Villasenor, J. D., Klein, H. P. and Groot, J. 1994. On the use of multifrequency and polarimetric radar backscatter features for classification of agricultural crops. International Journal of Remote Sensing. 15(9): 1799-1812.

Haldar, D., Das, A., Mohan, S., Pal, O., Hooda, R.S. and Chakraborty, M. 2012. Assessment of L-band SAR data at different polarization combinations for crop and other land use classification. Program in Electromagnetic Research $B$. (PIER). 36 (36): 303-321.

Hoekman, D. H., and Bouman, B. A. M. 1993. Interpretation of $\mathrm{C}$ - and $\mathrm{X}$-band radar images over an agricultural area, the Flevoland test site in the agriscatt-87 campaign. International Journal of Remote Sensing. 14: 1577-1594. 
Kuemmerle, T., Erb, K., Meyfroidt, P., Müller, D., Verburg, P. H., Estel, S. and Reenberg, A. 2013. Challenges and opportunities in mapping land use intensity globally. Current Opinion in Environmental Sustainability. 5(5), 484 493.

Kurosu, T., Fujita, M. and Chiba, K. 1995. Monitoring of rice crop growth from space using the ERS-1 C-band SAR. Transaction on Geoscience and Remote Sensing. 33(4):1092-1096.

Lee, J.S., Grunes, M.R. and Pottier, E. 2001. Quantitative comparison of classification capability: Fully polarimetric versus dual-and singlepolarization SAR. Transactions on Geoscience and Remote Sensing. 39(11): 2343-2351.

Panigrahy, R.K. and Mishra, A.K. 2013. An Unsupervised Classification of scattering behaviour using Hybrid Polarimetry. Radar, Sonar \& Navigation. 7(3): 270- 276.

Schotten, C. G. J., Van Rooy, W. W. L. and Janssen, L. L. F. 1995. Assessment of the capabilities of multi-temporal ERS-1 SAR data to discriminate between agricultural crops. International Journal of Remote Sensing. 16(14): 2619-2637.

Skriver, H., Morten, T. S. and Thomsen, A. G. 1999. Multitemporal $\mathrm{C}$ and L-band polarimetric signatures of crops. Transactions on Geoscience and Remote Sensing. 37(5): 2413-2429.

Toan, L.T., Laur, H., Mougin, E. and Lopes, A. 1989. Multitemporal and dualpolarization observations of agricultural vegetation covers by X-band SAR images. Transaction on Geoscience and Remote Sensing. 27(6): 709-717.
Torres, R., Snoeij, P., Geudtner, D., Bibby, D. Davidson, M., Attema, E., Potin, P., Rommen, B., Floury, N., Brown, M., Traver, I., Deghaye, P., Duesmann, B., Rosich, B., Miranda, N., Bruno, C., Abbate, M., Croci, R. and Rostan, F. (2012). GMES Sentinel-1 mission. Remote Sensing of Environment.120, 924.

Turkar, V., Deo, R., Rao, Y.S., Mohan, S. and Das, A. 2012. Classification accuracy of multi-frequency and multi-polarization SAR images for various land covers. Journal of Selected Topics in Applied Earth Observations and Remote Sensing. 5(3): $936-941$.

Ulaby, F.T., Held, D., Dobson, M.C., McDonald, K.C. and Thomas, B.A. 1987. Relating polarization phase difference (PPD) of SAR signals to scene properties. Transactions on Geoscience and Remote Sensing. 25(1): 83-91.

Wagner, W., Sabel, D., Doubkova, M., Hornáček, M., Schlaffer, S. and Bartsch, A. 2012. Prospects of Sentinel- 1 for land applications. In: IEEE International Geoscience and Remote Sensing Symposium, Munich, July 2012.Germany, pp.1741-1744.

Wang, J.R. and Mo, T. 1990. The polarization phase difference of orchard trees. International Journal of Remote Sensing. 11 (7): 1255-1265.

Wang, X., Ge, X. and Li, X. 2012. Evaluation of filters for Envisat ASAR speckle suppression in pasture area. In: $22^{\text {nd }}$ International Society for Photogrammetry and Remote Sensing Congress, Melbourne, September 2012. Australia, pp. 341-346.

\section{How to cite this article:}

Chetan Kumar Bhatt and Nain, A.S. 2018. Rice Acreage Estimation Using Sentinel-1A Dual Polarised SAR Data in Udham Singh Nagar (Uttarakhand). Int.J.Curr.Microbiol.App.Sci. 7(04): 2593-2599. doi: https://doi.org/10.20546/ijcmas.2018.704.295 